\title{
Penetrating injuries in Germany - epidemiology, management and outcome an analysis based on the TraumaRegister $\mathrm{DGU}^{\otimes}$
}

D Bieler ${ }^{1,2^{*}}$, E Kollig ${ }^{1}$, L Hackenberg ${ }^{1}$, JH Rathjen ${ }^{1}$, R Lefering ${ }^{3}$, A Franke ${ }^{1}$ and the Committee on Emergency Medicine, Intensive Care and Trauma Management(Sektion NIS) of the German Trauma Society (DGU)

\begin{abstract}
Background: The management of penetrating wounds is a rare challenge for trauma surgeons in Germany and Central Europe as a result of the low incidence of this type of trauma. In Germany, penetrating injuries are reported to occur in $4-5 \%$ of the severely injured patients who are enrolled in the TraumaRegister DGU ${ }^{\circledast}$ (trauma registry of the German Trauma Society). They include gunshot injuries, knife stab injuries, which are far more common, and penetrating injuries of other origin, for example trauma caused by accidents. The objective of this study was to assess the epidemiology and outcome of penetrating injuries in Germany, with a particular focus on the level of care provided by the treating trauma centre to gain more understanding of this trauma mechanism and to anticipate the necessary steps in the initial treatment.
\end{abstract}

Materials and methods: Since 2009, the TraumaRegister DGU ${ }^{\circledR}$ has been used to assess not only whether a trauma was penetrating but also whether it was caused by gunshot or stabbing. Data were taken from the standard documentation forms that participating German hospitals completed between 2009 and 2018. Excluded were patients with a maximum abbreviated injury scale (MAIS) score of 1 with a view to obtaining a realistic idea of this injury entity, which is rare in Germany.

\footnotetext{
* Correspondence: dan.bieler@uni-duesseldorf.de

'Department of Orthopaedics and Trauma Surgery, Reconstructive Surgery,

Hand Surgery, Plastic Surgery and Burn Medicine, German Armed Forces

Central Hospital, Koblenz, Germany

${ }^{2}$ Department of Orthopaedics and Trauma Surgery, Medical Faculty and

University Hospital Düsseldorf, Heinrich-Heine-University, Moorenstraße 5,

40225 Düsseldorf, Germany

Full list of author information is available at the end of the article
}

C C The Author(s). 2021 Open Access This article is licensed under a Creative Commons Attribution 4.0 International License, which permits use, sharing, adaptation, distribution and reproduction in any medium or format, as long as you give appropriate credit to the original author(s) and the source, provide a link to the Creative Commons licence, and indicate if changes were made. The images or other third party material in this article are included in the article's Creative Commons licence, unless indicated otherwise in a credit line to the material. If material is not included in the article's Creative Commons licence and your intended use is not permitted by statutory regulation or exceeds the permitted use, you will need to obtain permission directly from the copyright holder. To view a copy of this licence, visit http://creativecommons.org/licenses/by/4.0/. The Creative Commons Public Domain Dedication waiver (http://creativecommons.org/publicdomain/zero/1.0/) applies to the data made available in this article, unless otherwise stated in a credit line to the data. 
Results: From 2009 to 2018, there were 1123 patients with gunshot wounds, corresponding to a prevalence rate of $0.5 \%$, and 4333 patients with stab wounds (1.8\%), which were frequently caused by violent crime. The high proportion of intentionally self-inflicted gunshot wounds to the head resulted in a cumulative mortality rate of $41 \%$ for gunshot injuries. Stab wounds were associated with a lower mortality rate (6.8\%). Every fourth to fifth patient with a gunshot or stab wound presented with haemorrhagic shock, which is a problem that is seen during both the prehospital and the inhospital phase of patient management. Of the patients with penetrating injuries, $18.3 \%$ required transfusions. This percentage was more than two times higher than that of the basic group of patients of the TraumaRegister DGU® ${ }^{\oplus}$, which consists of patients with a MAIS $\geq 3$ and patients with a MAIS of 2 who died or were treated on the intensive care unit.

Conclusions: In Germany, gunshot and stab wounds have a low incidence and are mostly caused by violent crime or attempted suicides. Depending on the site of injury, they have a high mortality and are often associated with major haemorrhage. As a result of the low incidence of these types of trauma, further data and analyses are required in order to provide the basis for evaluating the long-term quality of the management of patients with stab or gunshot wounds.

Keywords: gunshvot wound, stab wound, TraumaRegister DGU», penetrating injuries, Germany, epidemiology

\section{Introduction}

As a result of the low incidence of gunshot and stab wounds in Germany and Central Europe, the management of these types of penetrating injuries is a rare challenge for surgeons during and after resuscitation room care. In Germany, penetrating injuries are reported to occur with an incidence of $4.1 \%$.[1] Apart from annual policerecorded crime statistics (Polizeiliche Kriminalstatistik, $P K S)$ on the use of firearms and stab weapons in association with criminal offences, no robust data on the epidemiology of associated injuries are available in Germany.
Crime statistics, too, provide only limited information on injury patterns and in particular on the severity of injuries since these data are collected on the basis of legal criteria and have not yet been processed for medical purposes.

According to police-recorded crime statistics from 2018, a total of 8343 incidents involving the use of firearms were reported in Germany. This figure is consistent with the downward trend of previous years. In 3819 $(46 \%)$ of the registered cases, firearms were used as a threat but not actually fired. In $54 \%(n=4524)$ of the cases, firearms were actually fired (Fig. 1).[2] These

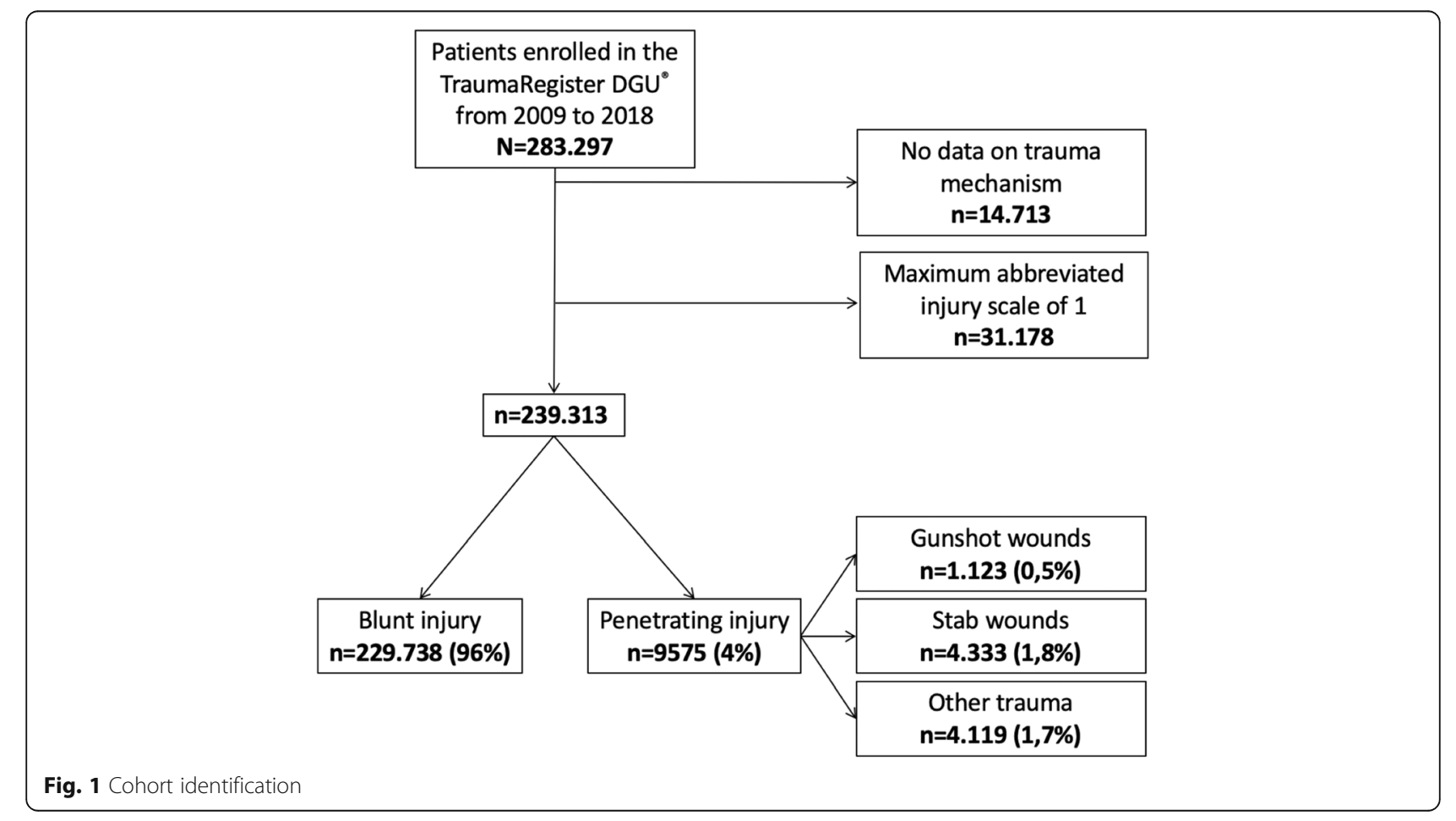


statistical data do not include the use of firearms by law enforcement officers but are limited to criminal offences.

Although a certain number of cases may have gone unreported, these figures provide a realistic idea of the incidence of gunshot wounds in Germany. Crime statistics can neither answer the question as to what clinical role and what demand for resources are associated with the management of this injury entity in civilian trauma centres, nor do they provide a precise picture of injury patterns and outcomes.

Since prospective studies on this matter are currently not available in Germany, we conducted a retrospective investigation on the basis of the TraumaRegister DGU ${ }^{\circ}$ (trauma registry of the German Trauma Society).

The objective of this study was to assess how often patients with gunshot and stab wounds were treated in the resuscitation room and what injury patterns they presented. We not only assessed patient demographics, the location of injury (extremities or body cavities), prehospital treatment, and inhospital treatment but, where possible, also collected data on the length of hospital stay and mortality.

We know from the literature that penetrating injuries can develop in a very dynamic manner.[3] For this reason, it is important to know what criteria indicate the need for specific treatment and what resources must be held available and are required. The present study also addressed these aspects.

Such a cohort design creates a bias since the study does not include data, for example, on patients who sustained only minor gunshot injuries and were not admitted to the resuscitation room or who received initial (and definitive) treatment in a hospital that does not participate in the TraumaRegister DGU ${ }^{\circ}$. There is, however, currently no German database or similar registry that can provide the basis for a general and comprehensive analysis covering a period of several years.

\section{Materials and methods}

The TraumaRegister DGU ${ }^{\bullet}$ of the German Trauma Society (Deutsche Gesellschaft für Unfallchirurgie, DGU) was founded in 1993. The aim of this multi-centre database is the pseudonymised and standardised documentation of severely injured patients.

Data are collected prospectively in four consecutive time phases from the site of the incident until discharge from hospital: (A) prehospital phase, (B) emergency/resuscitation room and initial surgery, $(C)$ intensive care unit, and (D) discharge. Documentation includes detailed information on demographics, injury patterns, comorbidities, prehospital and inhospital management, course on intensive care unit, relevant laboratory findings including transfusion data, and outcome. Included are patients who are admitted to hospital via the resuscitation room and subsequently receive intensive or intermediate care and patients who arrive at hospital with vital signs and die before admission to the intensive care unit.

The infrastructure for documentation, data management, and data analysis is provided by the Academy for Trauma Surgery (Akademie der Unfallchirurgie $\mathrm{GmbH}$, AUC), which is affiliated with the German Trauma Society. Scientific leadership is provided by the Committee on Emergency Medicine, Intensive Care and Trauma Management (Sektion NIS) of the German Trauma Society. Participating hospitals submit their pseudonymised data to a central database via a web-based application. Scientific data analysis is approved according to a peer review procedure established by Sektion NIS.

The participating hospitals are primarily located in Germany $(90 \%)$, but a growing number of hospitals in other countries contribute data as well (i.e. Austria, Belgium, China, Finland, Luxembourg, Slovenia, Switzerland, the Netherlands, and the United Arab Emirates). Currently, approximately 33,000 cases (basic group of patients) from more than 650 hospitals are entered into the database per year.

Participation in TraumaRegister DGU ${ }^{\circ}$ is voluntary. For hospitals associated with the TraumaNetzwerk $\mathrm{DGU}^{\circ}$, the entry of at least a basic data set is obligatory for reasons of quality assurance. Approximately $50 \%$ of all cases, however, are documented on the basis of the standard dataset.

Since 2009, the TraumaRegister DGU ${ }^{\circ}$ has been used to assess not only whether a trauma was penetrating but also whether it was caused by gunshot or stabbing. These data allowed us to identify relevant cases and to define the study period. We distinguished three subgroups of injuries, i.e. gunshot wounds, stab wounds, and other penetrating injuries.

Data were taken from the standard documentation forms that participating German hospitals completed between 2009 and 2018. Excluded were patients with a maximum abbreviated injury scale (AIS) score of 1 . We did not specify any other exclusion criteria in order to obtain as comprehensive a picture as possible of the injury entities investigated in this study.

As a result of the high proportion of gunshot wounds to the head (anatomical AIS body region code 1: head without face and facial bones) and the high overall mortality rates that are reported in the literature for these injuries, a subgroup of patients with head injuries was analysed as well. In addition, we analysed two-cavity injuries (thoracic and abdominal injuries) because of their clinical and therapeutical relevance. Inclusion and exclusion criteria were identical for all subgroups.

Primary endpoints were mortality and length of hospital stay. Secondary endpoints were transfusions (units 
of packed red blood cells), massive transfusions (more than 10 units of packed red blood cell units), fluid administration, chest drain insertion for thoracic injuries with an AIS $\geq 3$. Other secondary endpoints were emergency operations, which were not registered in a standardised manner during the study period. For this reason, the analysis of emergency operations was limited to cases that were reported from 2015 to 2018 since data on different types of emergency operations have been entered into the registry only since 2015. Especially emergency thoracotomy for thoracic injuries and emergency laparotomy for abdominal injuries were defined as secondary endpoints in the analysis of cases from 2015 to 2018 since every emergency operation - and not only the first emergency surgical procedure - was registered from that time on.

SPSS $^{\circ}$ (version 24, IBM Corp., Armonk, NY, United States) was used for the analysis of descriptive statistics. Numbers of cases, percentages, means, and standard deviations (SD) were provided. Because of the large number of cases and the wide variety of possible comparisons (multiple parameters, three-group comparisons), formal statistical tests were performed only for specific variables (e.g. rescue times). The chi-squared test was used for categorical variables, and the MannWhitney $U$ test and the Kruskal-Wallis test were used for metric variables. Missing data were handled by using pairwise case exclusion.

Differences in time of more than five minutes, in percentages of $5 \%$ or more, and in volume of more than $250 \mathrm{~mL}$ were regarded as clinically relevant.

The study was performed in accordance with the publication guideline of the TraumaRegister $\mathrm{DGU}^{\circ}$ and is registered as TR-DGU Project ID 2016-031. Since the study was a retrospective anonymised analysis, ethical approval was not required according to the regulations of the responsible regional medical association.

\section{Results}

Between 2009 and 2018, there were 9575 patients with a penetrating injury, accounting for $4.0 \%$ of the cohort of patients with an AIS $>1$ and with data on trauma mechanism.

Of these, 1123 had a gunshot injury, which corresponds to $0.5 \%$ of the study cohort, and 4333 had a stab wound, which corresponds to $1.8 \%$ of the cohort. These types of injury thus accounted for more than half (57\%) of the penetrating injuries that were included in the TraumaRegister DGU ${ }^{\circ}$ (Fig. 1).

\section{General data}

The majority of patients with penetrating injuries were male $(89.3 \%)$. The mean / median patient age was 44 / 42 years. Gunshot injuries were associated with a mean / median injury severity score (ISS) of 22.9 / 25, which was the highest overall injury severity score of all three subgroups. Patients with stab wounds had the lowest ISS on admission (mean 13.9; median 10) and patients with other penetrating trauma had a mean / median ISS of 17.5 / 14 (Table 1). According to documented diagnoses, patients with penetrating injuries rarely presented with single injuries. A median of three diagnoses was documented for patients with gunshot and stab wounds. Patients with other penetrating injuries had a median of four diagnoses. Furthermore, patients with penetrating injuries were often treated in (supraregional) level 1 trauma centres. The percentage of gunshot injuries that were managed in level 1 trauma centres was particular high $(72.2 \%)$. Patients with penetrating injuries were rarely treated in local (level 3) trauma centres, accounting for $4.9-11 \%$ of the subgroups.

\section{Trauma mechanism}

An isolated analysis of the gunshot wounds that were included in the registry between 2009 and $2018(n=1123)$ and were treated in the resuscitation room showed that $55.8 \%$ of the cases were intentionally self-inflicted injuries. By contrast, accidents involving the use of firearms accounted for only a small annual number of cases $(n=$ $10)$. Violent crime was suspected as the cause of gunshot injuries in $34.5 \%$ of cases.

Compared with the number of gunshot injuries, almost twice as many stab wounds (59.4\%) were caused by violent crime, whereas suicide attempts accounted for only $30.8 \%$ of stab wounds that were managed in the resuscitation room. Accidents were the cause of stab wounds in only $9.8 \%$ of cases. Other penetrating injuries were associated with a completely different distribution of injury mechanisms (Fig. 2).

Heterogeneous causes of injury were identified through an analysis of trauma mechanisms in the group of patients with penetrating injuries other than gunshot or stab wounds (Fig. 3). These injuries were most commonly caused by traffic accidents involving cars $(15.5 \%)$ and motorcycles $(14.2 \%)$ and by other trauma (26.1\%). Traffic accidents involving cyclists and pedestrians accounted for $7-8 \%$ each and falls for approximately $23 \%$ of other penetrating injuries.

\section{Patterns of injury}

In the subgroup of patients with gunshot injuries, the head (52.2\%) was the most commonly affected anatomical region, followed by the chest $(23.9 \%)$ and the abdomen (20.4\%). Injuries to the extremities were documented in $19.7 \%$ of cases with gunshot injuries.

Stab wounds most commonly involved the chest (52\%) and the abdomen (37.4\%). At least one of these 
Table 1 General data $(m=$ mean, $S D=$ standard deviation, $I Q R=$ interquartile range, ASA = American Society of Anesthesiologists, ISS = injury severity score)

\begin{tabular}{|c|c|c|c|c|c|c|}
\hline \multirow[b]{2}{*}{ Male (n) } & \multicolumn{2}{|c|}{ Gunshot $(n=1123)$} & \multicolumn{2}{|c|}{ Stab $(n=4333)$} & \multicolumn{2}{|c|}{ Other $(n=4119)$} \\
\hline & 1001 & $89.3 \%$ & 3627 & $83.8 \%$ & 3125 & $76.1 \%$ \\
\hline Age (m) & 52.6 & SD 21 & 39.4 & SD 17.2 & 46.8 & SD 21.3 \\
\hline Age (median, IQR) & 53 & $(36-71)$ & 36 & $(26-51)$ & 47 & $(28-62)$ \\
\hline Age $>70$ years $(n)$ & 306 & $27.3 \%$ & 301 & $7.0 \%$ & 1324 & $13.9 \%$ \\
\hline Age > 16 years $(n)$ & 11 & $1.0 \%$ & 66 & $1.5 \%$ & 186 & $4.5 \%$ \\
\hline Level 1 trauma care & 811 & $72.2 \%$ & 2474 & $57.1 \%$ & 2414 & $58.6 \%$ \\
\hline Level 2 trauma care & 257 & $22.9 \%$ & 1364 & $31.5 \%$ & 1226 & $29.8 \%$ \\
\hline Level 3 trauma care & 55 & $4.9 \%$ & 473 & $10.9 \%$ & 455 & $11.0 \%$ \\
\hline ASA class 3-4 & 191 & $19.6 \%$ & 371 & $9.4 \%$ & 442 & $12.1 \%$ \\
\hline ISS (m) & 22.9 & SD 15.2 & 13.9 & SD 10.1 & 17.5 & SD 12.8 \\
\hline ISS (median, IQR) & 25 & $\begin{array}{l}(12,13,14,15,16,17,18,19,20,21,22, \\
23,24,25,26)\end{array}$ & 10 & $\begin{array}{l}(8,9,10,11,12,13,14,15 \\
16,17,18)\end{array}$ & 14 & $\begin{array}{l}(9,10,11,12,13,14,15,16,17,18,19 \\
20,21,22)\end{array}$ \\
\hline $\begin{array}{l}\text { Number of documented diagnoses } \\
\text { (median, IQR) }\end{array}$ & 3 & $(2,3,4,5)$ & 3 & $(2,3,4)$ & 4 & $(2,3,4,5,6)$ \\
\hline
\end{tabular}

\section{Trauma mechanism}

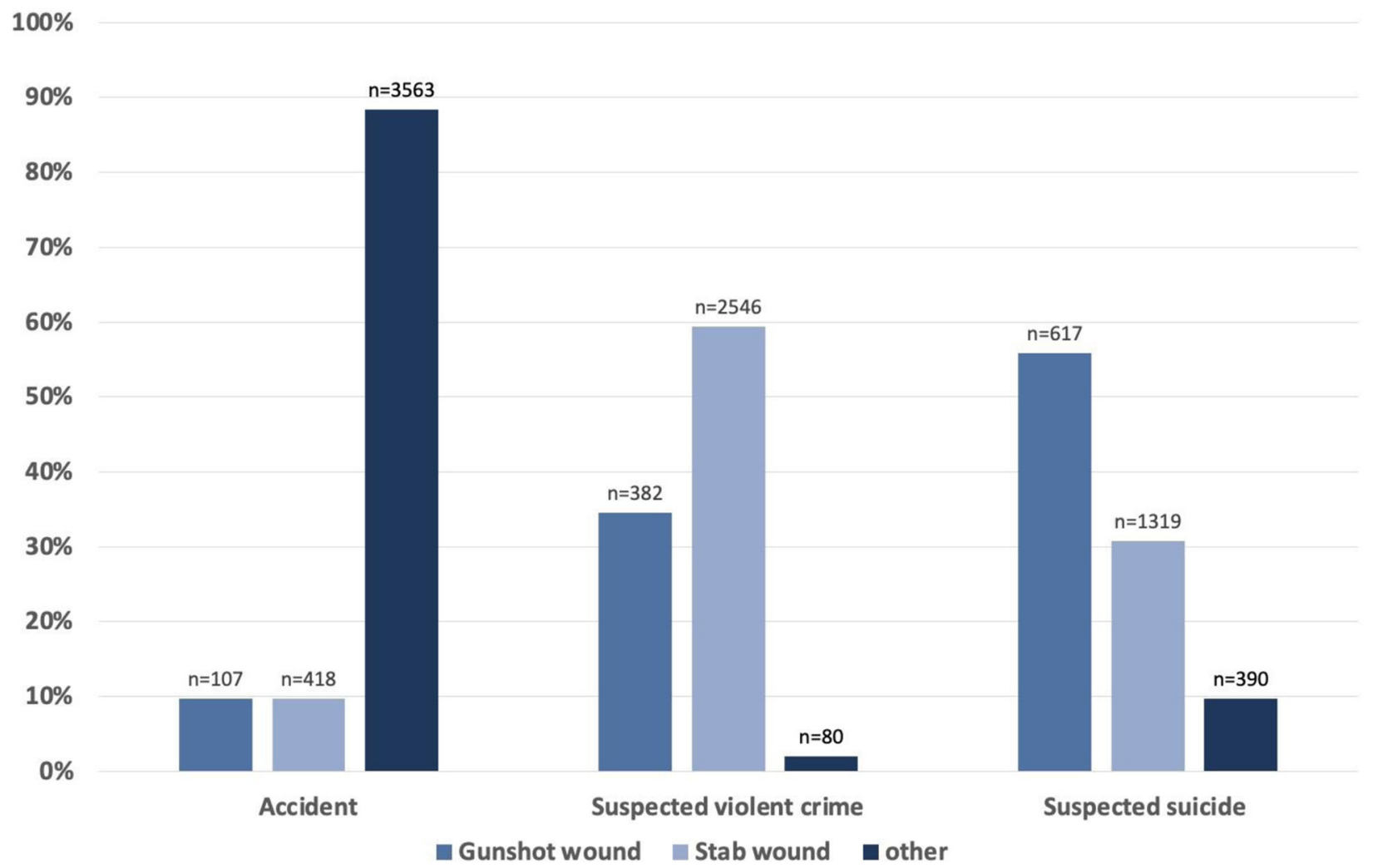

Fig. 2 Distribution of trauma mechanisms in the three subgroups of TraumaRegister DGU ${ }^{\otimes}$ patients with penetrating injuries $(n=9575)$ (other $=$ other mechanisms of trauma, $n=$ number of cases) 


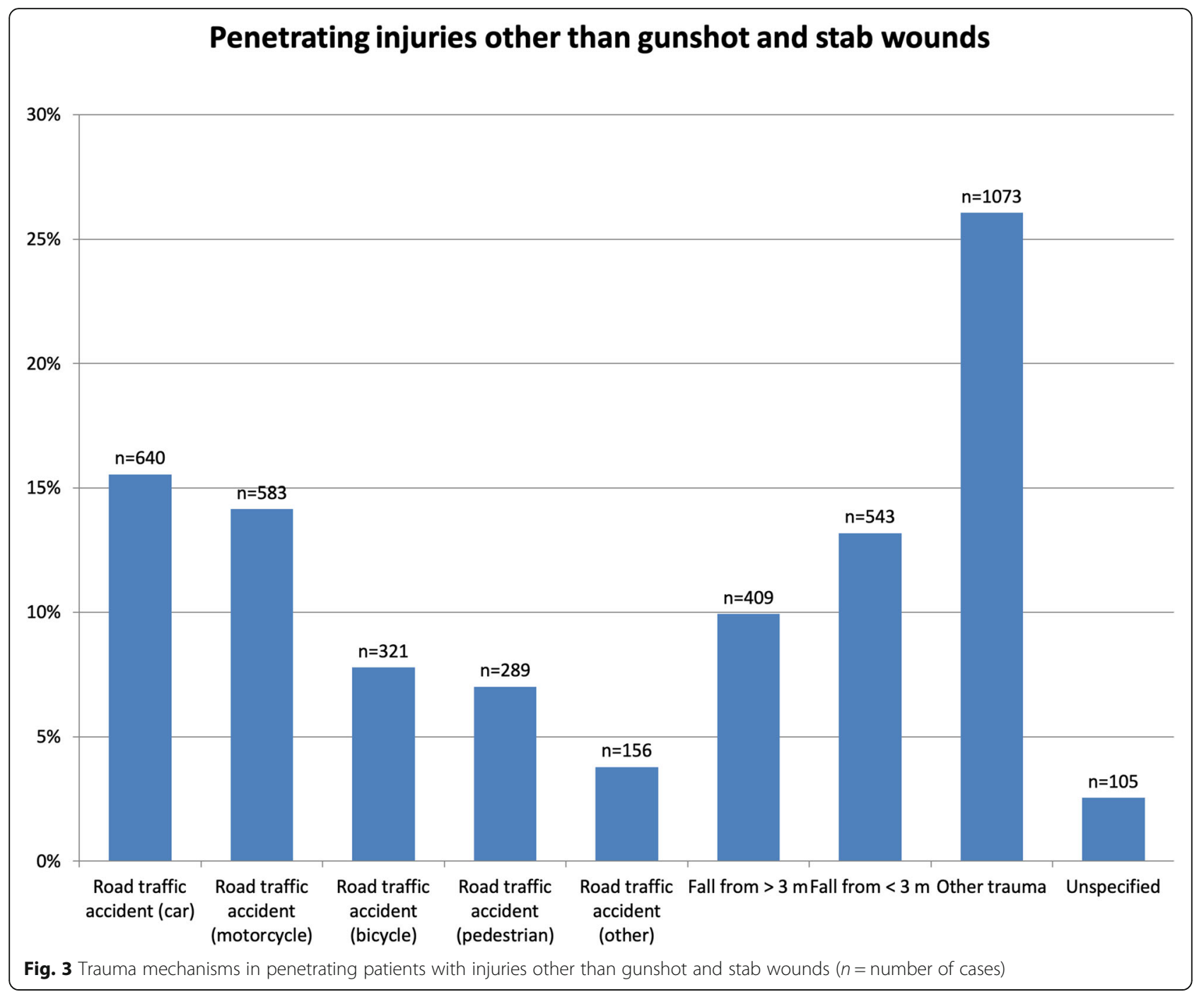

two cavities was affected in $76 \%$ of the documented cases.

Penetrating injuries other than gunshot and stab wounds involved the head (34.3\%), the chest (33.6\%), and the upper $(35.6 \%)$ and lower $(41.3 \%)$ extremities.

Figure 4 provides a detailed overview of the distribution of injuries.

An analysis of two-cavity injuries revealed that more than a quarter of thoracic stab wounds also involved the abdomen and that almost half of the gunshot injuries to the chest $(44 \%)$ also affected the abdominal region. More than $50 \%$ of abdominal gunshot injuries and $37 \%$ of abdominal stab wounds also involved the chest. Other penetrating abdominal injuries also affected the chest in almost $60 \%$ and other penetrating thoracic injuries also involved the abdomen in $23 \%$ (Fig. 5).

Registry data from 2015 to 2018 showed that $21.4 \%$ of the patients with thoracic trauma underwent acute thoracotomy. The majority of these patients (38.8\%) had sustained gunshot injuries. Urgent laparotomy was performed in $66.9 \%$ of the patients with penetrating abdominal injuries, the majority of whom presented with gunshot injuries $(76.5 \%)$. The decision to perform thoracotomy or laparotomy strongly depended on injury severity. Thoracotomy was performed in $8 \%$ and laparotomy in $53 \%$ of the patients with an AIS score of 2. By contrast, thoracotomy was performed in as much as $41 \%$ and laparotomy in as much as $81 \%$ of the patients with an AIS score of 5 .

\section{Prehospital and inhospital management}

Since head injuries accounted for a significantly higher percentage of gunshot injuries compared with stab and other penetrating injuries, gunshot injuries were also associated with a significantly lower Glasgow Coma Scale (GCS) score (Table 2, $p<0.001$ ) than other penetrating injuries. Furthermore, the on-scene time was considerably lower for stab 


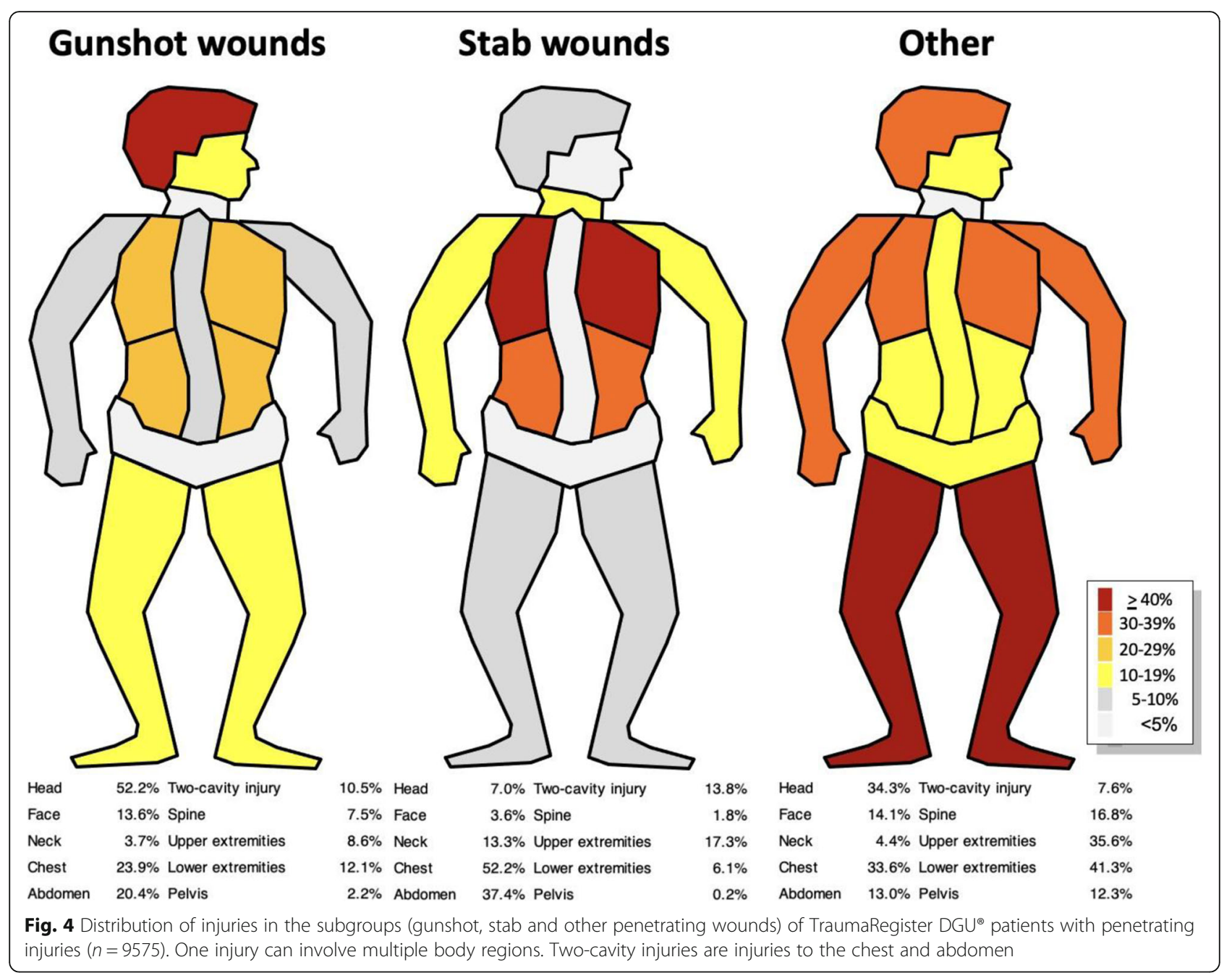

injuries (21.3 $\mathrm{min})$ than for gunshot injuries (29.5 min). Times from scene to hospital varied by up to three minutes. As a result, stab injuries were associated with significantly lower prehospital times than gunshot and other penetrating injuries $(p<$ 0.001) (Table 2). Air transportation was less commonly used for patients with stab wounds (only approximately $6 \%)$ than for the other patients $(p<$ 0.001).

Since patients with gunshot injuries had a lower GCS score, intubation was significantly more common in this patient group during prehospital management. Patients with gunshot injuries also more often required other types of prehospital treatment such as resuscitation, catecholamine therapy, and sedation.

Patients with penetrating injuries required chest drain insertion only rarely (approximately $5 \%$ ). Chest drains were placed in only about every tenth patient with a penetrating gunshot injury to the chest and in about every twentieth patient with a stab or other penetrating injury to the chest. Figure 6 shows how often the different types of penetrating thoracic injuries $(\mathrm{AIS} \geq 3$ ) mandated chest drain insertion in the prehospital setting and in the resuscitation room.

Apart from the small number of cases in which chest drains were placed during the prehospital phase, it is interesting to note that almost every second patient who underwent prehospital chest drain insertion required an additional chest drain or chest drain replacement in the resuscitation room.

An analysis of (massive) transfusion requirements for penetrating injuries within the first $48 \mathrm{~h}$ of admission shows heterogeneous results (Fig. 7). The pattern of injury had a significant effect on transfusion rates especially in patients with thoracic or abdominal injuries. The presence of thoracic or abdominal injuries was associated with up to three times higher transfusion rates. Massive transfusions too were required up to three times more often in patients with thoracic or abdominal injuries. 


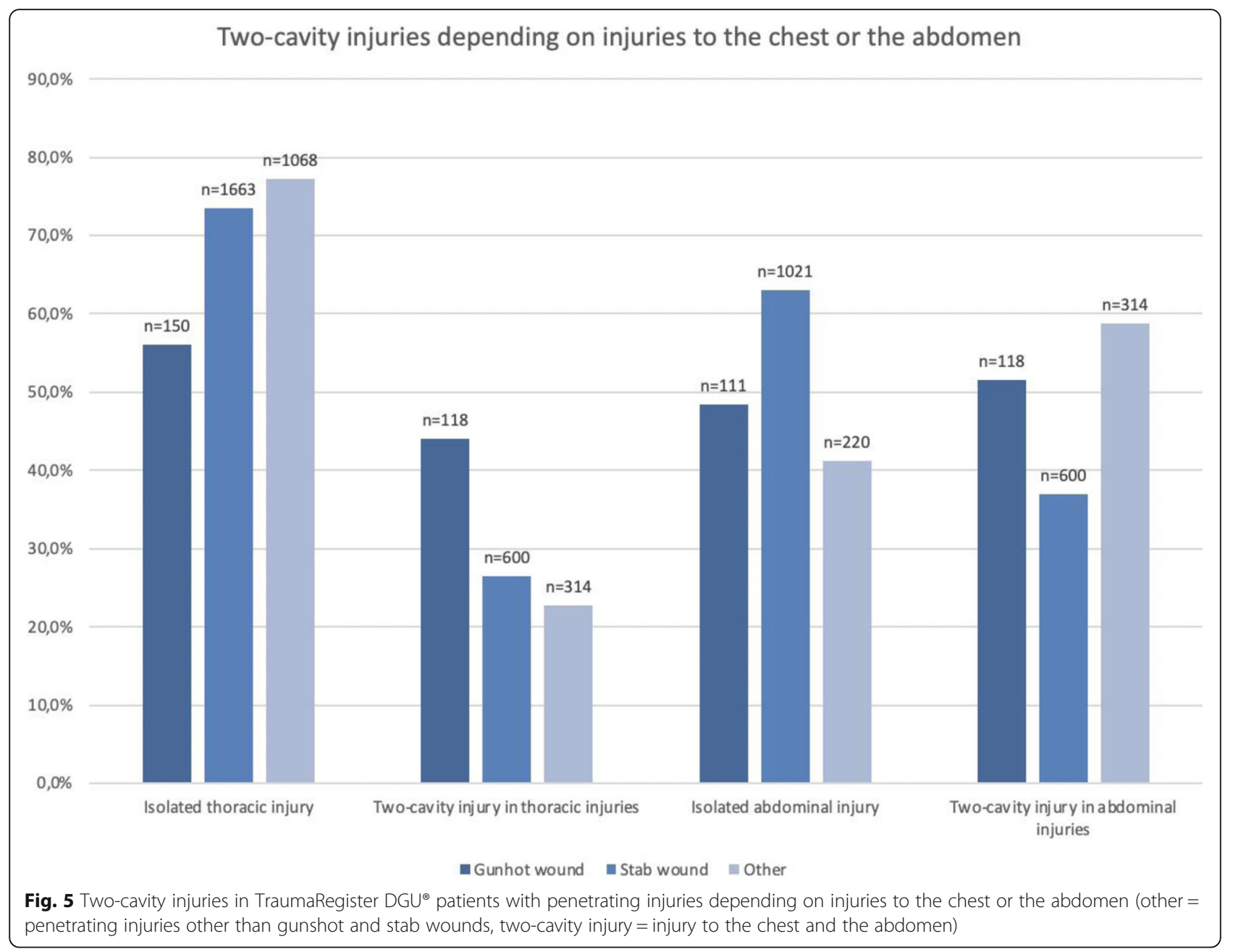

\section{Outcome}

As a result of the high proportion of suicide-related gunshot wounds to the head, the mean mortality rate for gunshot injuries was high (38.2\%) whereas the mortality rate for gunshot injuries that did not involve the head was considerably lower (13.3\%). Different results were obtained for the mortality rates in the other two subgroups (Table 2). Figure 8 shows the mortality rates for the different subgroups of penetrating injuries depending on the presence or absence of a traumatic brain injury. In the group of patients with gunshot injuries, $52.2 \%$ of those who died had a traumatic brain injury (TBI), either in isolation or in combination with other injuries. In the group of patients with stab wounds, $93 \%$ of those who died had no TBI. Revised Injury Severity Classification (RISC) II prognostic scores and standardised mortality rates (SMR) for the three groups of patients are shown in Table 2. Based on RISC II scores, gunshot injuries were associated with an increased SMR (1.07) whereas stab wounds (0.78) and other penetrating injuries (0.84) were associated with lower SMRs.

\section{Discussion}

This study is the first to provide an overview of penetrating injuries in Germany over a period of ten years. It is based on patients from the TraumaRegister DGU ${ }^{\circ}$ who met the criterion of having sustained potentially life-threatening injuries.

Registry data show that half of all penetrating injuries (4\%) are caused by gunshot or stabbing. This injury entity is thus considerably rarer in Germany than in the United States (20\%).[4]

Although a medical registry cannot replace crime statistics, it shows that the causes of perforating injuries are suspected suicide or violent crime in the majority of cases. Accidents involving the use of firearms or stabbing weapons are far less commonly documented. The incidence of these accidents is comparable to that reported in the United States.[4]

The total number of patients with penetrating injuries that were treated in resuscitation rooms in Germany was 9575 during the period from 2009 to 2018, corresponding to a mean annual number of 957 patients. 
Table 2 Prehospital and inhospital management (*only data from standard documentation forms were used since the QM documentation form does not include relevant parameters); GCS = Glasgow Coma Scale, ED = emergency department, RISC= Revised Injury Severity Classification, SMR = standardised mortality rate, $\mathrm{m}=$ mean, $\mathrm{SD}=$ standard deviation, $\mathrm{PRBC}=$ packed red blood cells, $\mathrm{Cl}=$ confidence interval

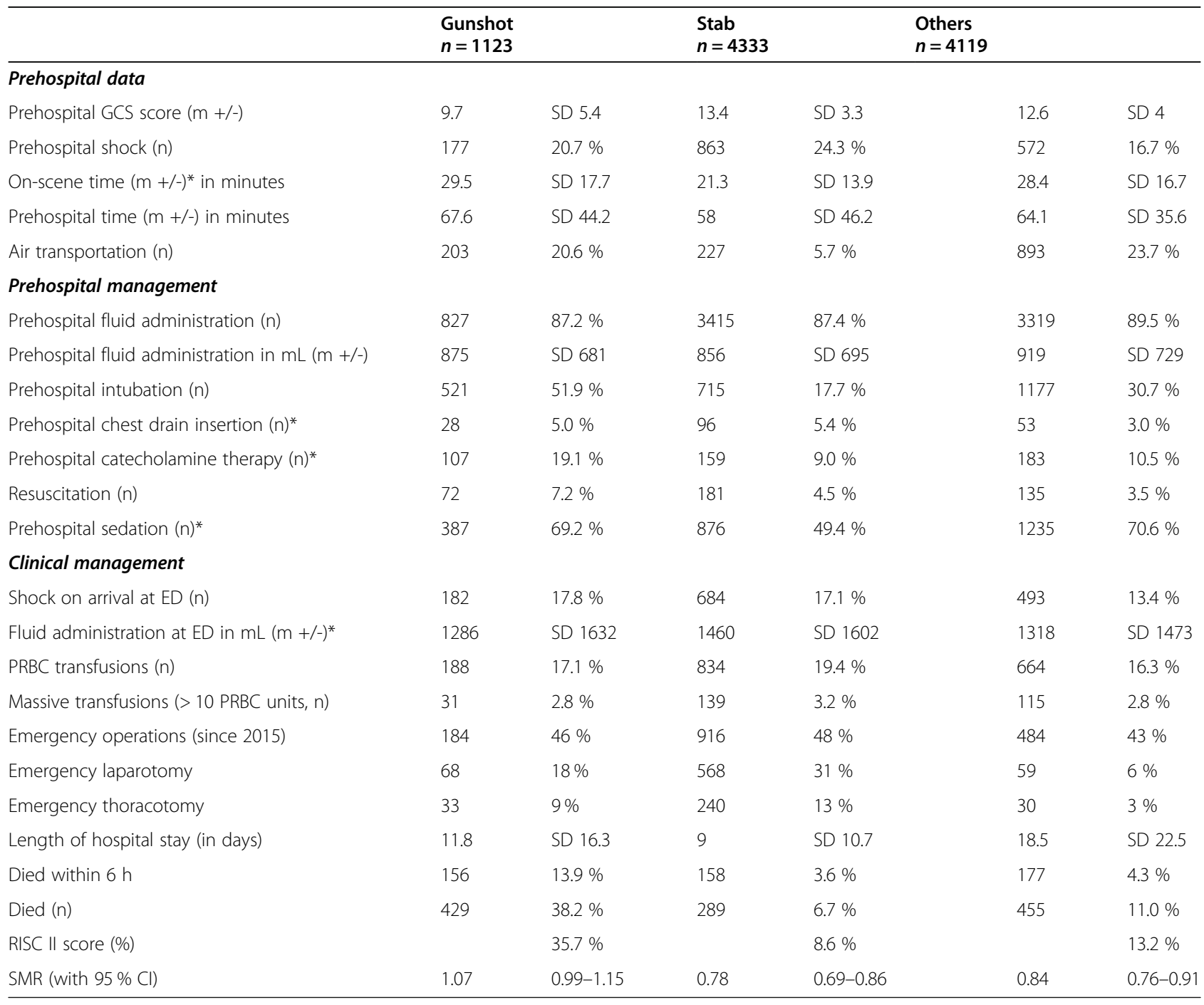

A decreased level of consciousness was documented as a leading life-threatening condition, especially in patients with a head injury caused by the use of firearms in suspected suicide attempts. Although these patients are managed by intubation and intensive care, their overall mortality rate is three to five times higher than that reported for patients without a gunshot injury to the head. It is interesting to note that gunshot injuries to the head are isolated injuries in approximately $50 \%$ of the cases. This percentage is similar to results from other studies, which too report mortality rates of more than $40 \%$ [5-7]. These patients usually require no intervention other than airway and circulatory procedures. The management of these patients focuses on deciding whether, depending on injury severity, emergency surgery or further diagnostic and imaging procedures should be performed [8].

Penetrating injuries involving other regions of the body may require a more differentiated treatment approach [3].

In this study, at least a fifth of the patients presented with a penetrating injury to the extremities. Several authors reported that the use of tourniquets significantly reduced mortality from exsanguination from extremity injuries [9-11]. Although tourniquets have been primarily used by the military, experience has in recent years encouraged the use of tourniquets also in the civilian setting with a view to avoiding preventable deaths from extremity haemorrhage with prehospital tourniquet 


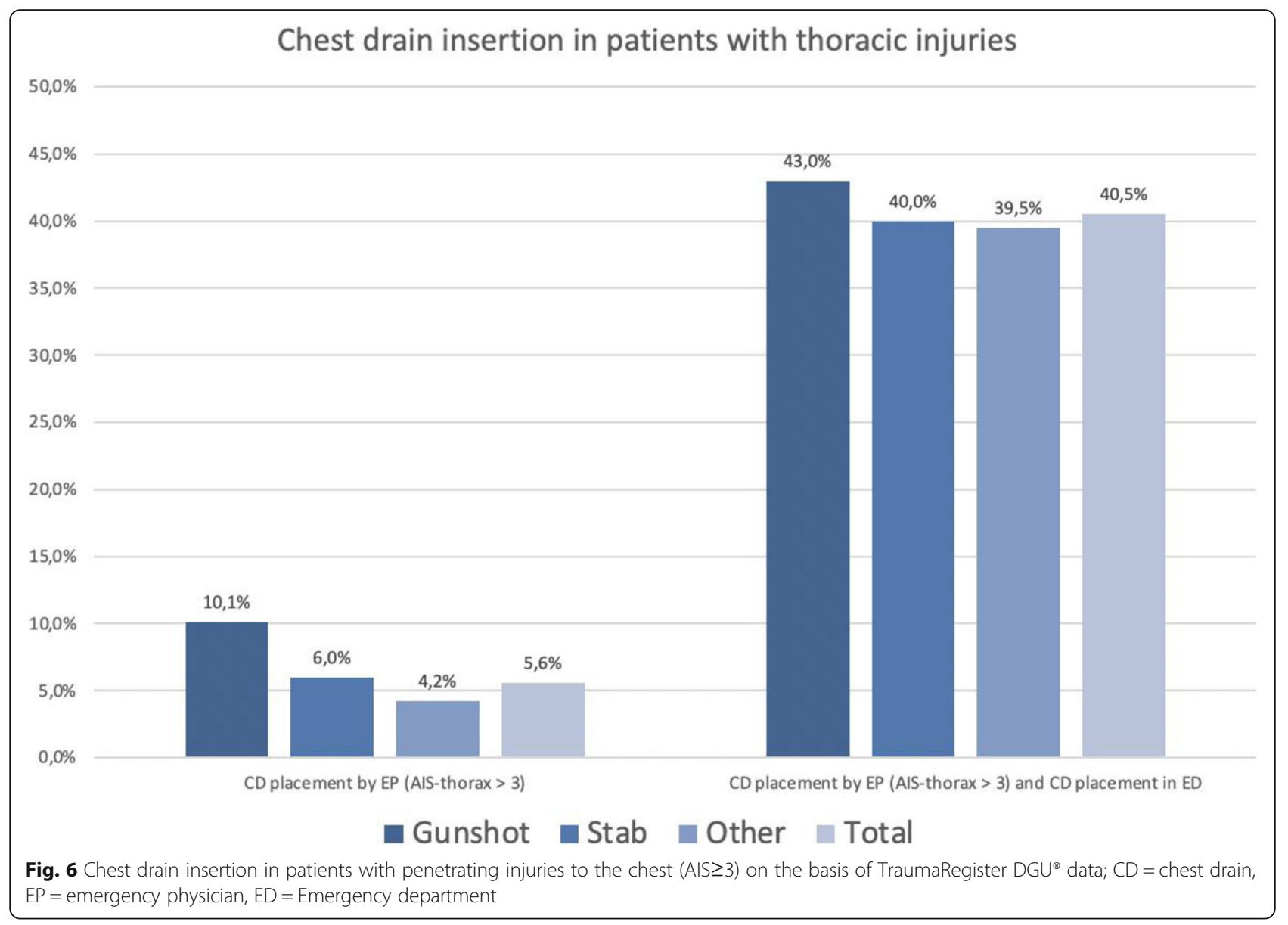

application [12]. As a result of this development, isolated extremity injuries are today associated with a low mortality rate since extremity haemorrhage can be easily and adequately controlled with tourniquets $[13,14]$. In our opinion, the risks of ischaemic or neurologic complications are acceptable given the fact that tourniquets can save lives. It should be noted that potential tourniquetrelated (ischaemic and pressure) damage can be expected to be fully reversible since prehospital rescue times of 68 min have been reported for gunshot wounds and $58 \mathrm{~min}$ for stab wounds in Germany $[15,16]$. Tourniquets should nevertheless only be used for specific indications. If the situation permits, pressure dressings continue to be the treatment of choice for non-spurting wounds.

Injuries involving one of the large body cavities (thoracic or abdominal cavity) also affect the other large body cavity in up to $50 \%$ of the cases and are referred to as two-cavity injuries. Haemodynamically stable patients $(75-80 \%$ in our cohort) undergo diagnostic computed tomography (CT) with a view to improving surgical planning. When the patient is positioned for surgery, the presence of a two-cavity injury must be assumed unless the involvement of both cavities can definitely be ruled out. Moreover, two-cavity injuries are associated with a significantly higher probability that the patient requires blood products. The results of this study are in line with those reported in the literature [17]. Emergency operations had to be performed almost twice as often in patients with penetrating injuries $(46 \%)$ than in the basic group of patients of the TraumaRegister $\mathrm{DGU}^{\circ}$ during the ten-year study period $(n=242,793$; emergency and early operations, $23.5 \%$ ) [1]. Emergency thoracic and abdominal operations for gunshot and stab wounds (thoracotomy, 9 and $13 \%$; laparotomy, 18 and $31 \%$ ) were required many times more often than for blunt injuries. Lögters et al. reported an emergency thoracotomy rate of $0.5 \%$ and an emergency laparotomy rate of $2.8 \%$ in a total of more than 12,000 patients, almost all of whom had sustained blunt trauma [18]. These results emphasise that the management of penetrating injuries in the resuscitation room requires the presence and expertise of surgeons from different specialties.

This requirement is underlined by the fact that approximately $25 \%$ of all patients with penetrating injuries presented with prehospital haemorrhagic shock 


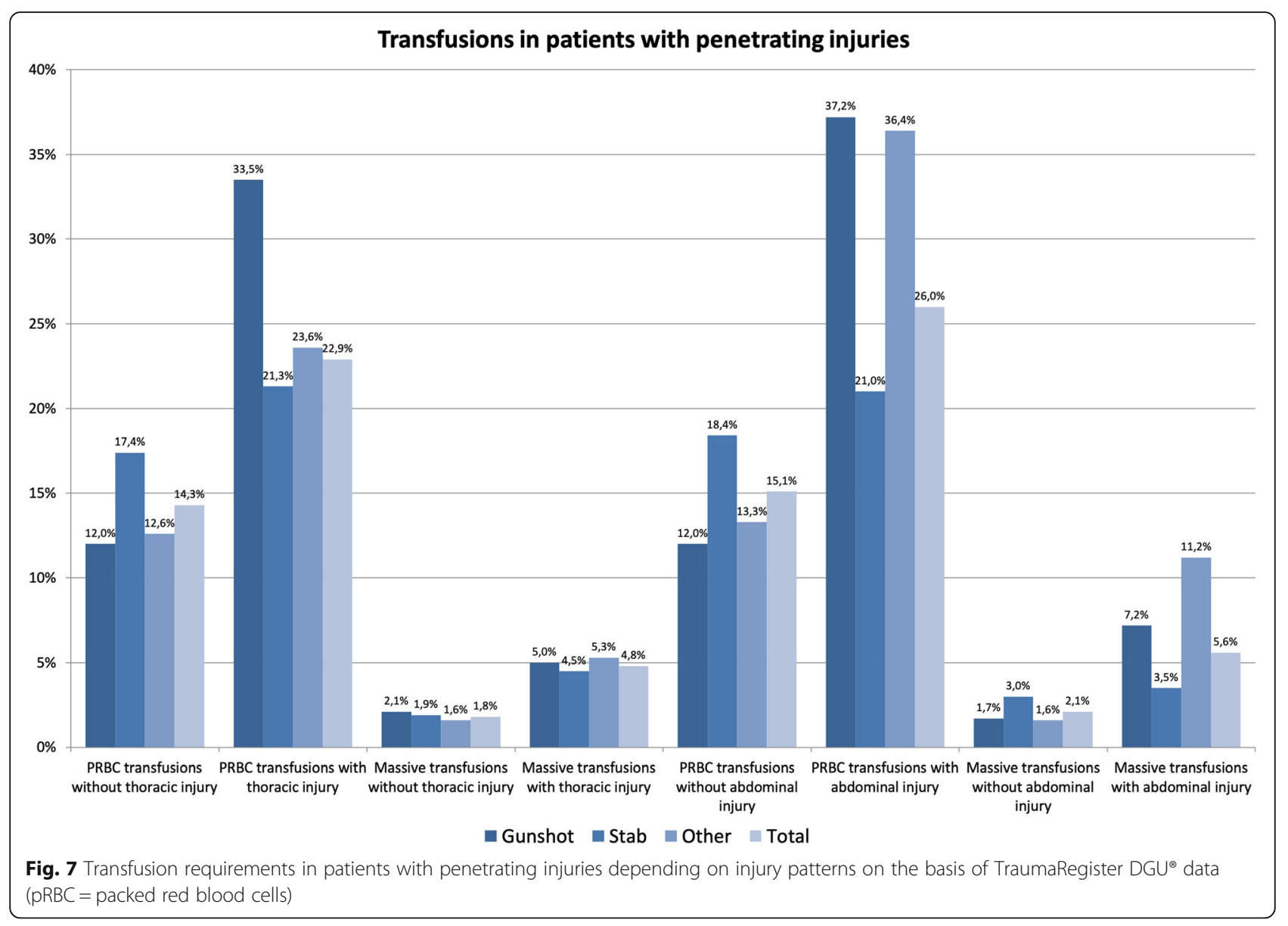

(systolic blood pressure $\leq 90 \mathrm{mmHg}$ ), which is one of the leading sources of clinical problems. By contrast, less than $10 \%$ of patients with blunt trauma are reported to have a haemorrhagic shock in the prehospital phase [1].

This is not surprising since many other studies found that exsanguation was the leading cause of death in patients with penetrating injuries $[12,19,20]$. Accordingly, patients with penetrating injuries require $\mathrm{pRBC}$ transfusions and massive transfusions within the first $48 \mathrm{~h}$ considerably more often than patients with blunt trauma. This is the case in approximately $37 \%$ of patients with abdominal injuries [1].

It is undisputed that the primary objective of clinical treatment is to control bleeding into the body cavities, which necessitates surgical intervention in the majority of cases. Permissive hypotension is an approach that is increasingly recommended for the prehospital management of bleeding in body cavities. In the current German S3 Guideline on the Treatment of Patients with severe and multiple injuries, permissive hypotension is a grade B recommendation for the management of actively bleeding patients, which means that this strategy "should" be used, and is contraindicated in patients with injuries to the central nervous system [21]. Recent literature increasingly suggests that permissive hypotension should be rigorously used until surgical control of bleeding has been achieved [22, 23]. Hussmann et al. even reported a survival advantage if this strategy is used [24, 25].

For many years, the TraumaRegister $\mathrm{DGU}^{\circ}$ has reported prehospital rescue times of approximately $70 \mathrm{~min}$ for patients with life-threatening injuries [1]. Prehospital rescue times for patients with gunshot or stab wounds are considerably shorter. For example, the rescue time for patients with stab wounds was $58 \mathrm{~min}$ and was thus 12 min shorter. Possible reasons may be a lower intubation rate, no need for technical rescue operations, the increased incidence of this injury entity in major cities with a high hospital density, or the use of the "scoop and run" strategy that was intuitively and correctly adopted by the emergency physician.

Penetrating thoracic injuries can lead to acute lifethreatening conditions that can be managed by a few simple measures in the prehospital setting. The simplest measure is needle decompression for tension pneumothorax [26]. Several authors recommend that patients with a suspected diagnosis of tension pneumothorax 


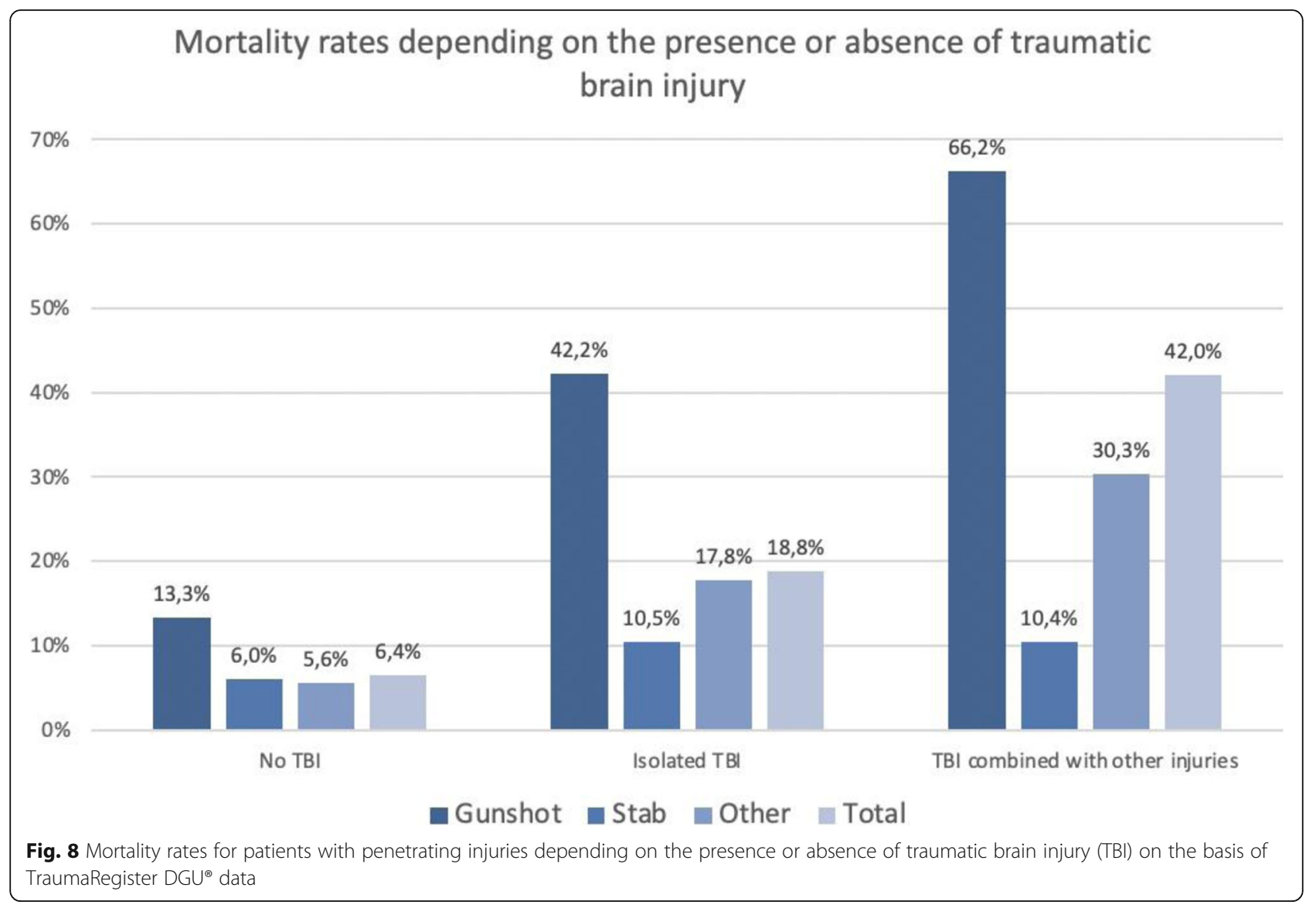

should be managed not only by primary decompression but also by prehospital chest drain insertion. Skin emphysema and serial rib fractures have been suggested as further indications for the prehospital placement of a chest drain in ventilated patients [27]. The current S3 Guideline too does not generally recommend prehospital chest insertion in patients with severe thoracic trauma. According to grade $\mathrm{B}$ recommendations, tension pneumothorax should be managed by surgical decompression with or without the placement of a chest drain and pneumothorax should be treated with a chest drain, if indicated [21]. Available data do not sufficiently explain why prehospital chest drain insertion was performed in only $5.6 \%$ of patients with penetrating thoracic trauma (10.1\% of patients with gunshot injuries, $6 \%$ of patients with stab wounds). Likewise, it is unclear to what extent this approach to the patient may have influenced mortality. Further studies should investigate this aspect and should also address the fact that more than $40 \%$ of the chest drains that were placed in the prehospital setting were considered insufficient or inadequate in the resuscitation room. Recently, prehospital clamshell thoracotomy [28] has been repeatedly brought into focus and should be further discussed since this procedure, which should only be performed by an experienced surgeon, causes additional major trauma.

\section{Limitations}

This is a retrospective analysis. A wide variety of factors may have a notable influence and should not be underestimated in the evaluation of findings. Especially the outcome of patients with severe penetrating injuries depends on a multitude of factors (e.g. experience of emergency medical service personnel, time and place of a trauma incident, receiving facility, rescue equipment and vehicles, and patient factors), which, in their entirety, cannot be assessed comprehensively in a register. Furthermore, it should be noted that patients who died in the prehospital setting are not included in the TraumaRegister $\mathrm{DGU}^{\circ}$ (trauma registry of the German Trauma Society). Another limitation of this study is that treatment limitations, for example on the basis of an advance health care directive, were not registered. This applies in particular to the care of patients with severe traumatic brain injury.

It should also be noted that not all German hospitals contribute data to the registry and thus not all patients with life-threatening gunshot and stab wounds were 
included in this study [1]. Accordingly, the documented and analysed cases on which this study is based are only a sample of patients with gunshot or stab wounds in Germany. Moreover, patients with minor penetrating trauma are not enrolled in the TraumaRegister DGU. For this reason, the results and conclusions on the overall number of penetrating injuries and especially stab wounds are limited.

\section{Conclusions}

In Germany, gunshot and stab wounds have a low incidence and are mostly caused by violent crime or attempted suicides. Nevertheless, they account for more than half of all penetrating injuries.

Depending on the body region affected, they are associated with a high mortality rate. Moreover, penetrating injuries often lead to a considerable loss of blood that requires early blood transfusion.

Injuries to the chest or abdomen are two-cavity injuries in $50 \%$ of the patients.

Because of the low incidence of these types of penetrating injuries, further data must be collected and analysed with a view to evaluating and improving the quality of long-term care for patients with gunshot and stab wounds. A particular focus should be placed on treatments that provide a survival advantage.

\begin{abstract}
Abbreviations
AIS: Abbreviated Injury Score; ASA: American Society of Anaesthesiologists; Cl: confidence interval; d: days; DGU: German Trauma Society; ED: emergency department; e.g.: exempli gratia; fig.: figure; GCS: Glasgow Coma Scale; ICU: intensive care unit; ISS: Injury Severity Score; m: male; pRBC: packed red blood cells; RISC: Revised Injury Severity Classification; SD: Standard deviation; Sektion NIS: Committee on Emergency Medicine, Intensive Care and Trauma Management; SMR: standardised mortality rate; TBI: traumatic brain injury
\end{abstract}

\section{Acknowledgements}

We would like to thank the members of the Polytrauma Study Group of the German Trauma Society for their many years of hard work and commitment to TraumaRegister DGU๑. In 2007, the Polytrauma Study Group was integrated into the Committee on Emergency Medicine, Intensive Care and Trauma Management (Sektion NIS) of the German Trauma Society (DGU).

\section{Authors' contributions}

DB: Conception and designing the study, conducting the study (data analysis and interpretation), drafting the manuscript. EK, LH, JHR, AF: Data interpretation, critically revising the manuscript. RL: Conception and designing the study, conducting the study (data analysis and interpretation), critically revising the manuscript. The author(s) read and approved the final manuscript.

\section{Funding}

There was no funding involved in the study. Open Access funding enabled and organized by Projekt DEAL.

\section{Availability of data and materials}

The datasets during and/or analysed during the current study available from the corresponding author on reasonable request.

\section{Declarations}

Ethics approval and consent to participate

Not applicable. The manuscript does not report on or involve the use of any animal or human tissue.

\section{Consent for publication}

Not applicable.

\section{Competing interest}

$\mathrm{DB}, \mathrm{RL}, \mathrm{AF}$ are members of the Committee on Emergency Medicine, Intensive Care and Trauma Management (Sektion NIS) of the German Trauma Society (DGU). RL is a consultant for AUC GmbH and has received research support (third-party funds) from AUC GmbH. DB is the speaker of working group TraumaRegister DGU ${ }^{\bullet}$ of the Committee on Emergency Medicine, Intensive Care and Trauma Management (Sektion NIS). The other authors declare that they have no financial competing interests. They received no financial funding.

\section{Author details}

'Department of Orthopaedics and Trauma Surgery, Reconstructive Surgery, Hand Surgery, Plastic Surgery and Burn Medicine, German Armed Forces Central Hospital, Koblenz, Germany. ${ }^{2}$ Department of Orthopaedics and Trauma Surgery, Medical Faculty and University Hospital Düsseldorf, Heinrich-Heine-University, Moorenstraße 5, 40225 Düsseldorf, Germany. ${ }^{3}$ Institute for Research in Operative Medicine, Witten/Herdecke University, Cologne, Germany.

Received: 20 December 2020 Accepted: 24 May 2021

Published online: 13 June 2021

\section{References}

1. Sektion Intensiv- \&. Notfallmedizin Schwerverletztenversorgung (NIS) der Deutschen Gesellschaft für Unfallchirurgie (DGU) \& AUC - Akademie der Unfallchirurgie GmbH. TraumaRegister DGU Jahresbericht 2019. (2019).

2. Bundeskriminalamt. Polizeiliche Kriminalstatistik 2018. (2018).

3. Franke A, et al. The First Aid and Hospital Treatment of Gunshot and Blast Injuries. Deutsches Arzteblatt International. 2017;114:237-43.

4. Kauvar DS, Wade CE. The epidemiology and modern management of traumatic hemorrhage: US and international perspectives. Crit Care. 2005;9 Suppl(5):1-9.

5. Folkerson LE, et al. Coagulopathy as a predictor of mortality after penetrating traumatic brain injury. Am J Emerg Med. 2018;36:38-42.

6. Regasa LE, et al. Mortality Following Hospital Admission for US Active Duty Service Members Diagnosed With Penetrating Traumatic Brain Injury, 20042014. J Head Trauma Rehabil. 2018;33:123-32.

7. Rosenfeld EH, et al. Defining Massive Transfusion in Civilian Pediatric Trauma With Traumatic Brain Injury. J Surg Res. 2019:236:44-50.

8. Skarupa DJ, et al. Trends in civilian penetrating brain injury: A review of 26,871 patients. Am J Surg. 2019;218:255-60.

9. Beekley AC, et al. Prehospital tourniquet use in Operation Iraqi Freedom: effect on hemorrhage control and outcomes. J Trauma. 2008;64:28-37. discussion $\mathrm{S37.}$

10. Kragh JF, et al. Survey of the indications for use of emergency tourniquets. $J$ Spec Oper Med. 2011;11:30-8.

11. Kragh JF Jr, et al. Survival with emergency tourniquet use to stop bleeding in major limb trauma. Ann Surg. 2009;249:1-7.

12. Passos $E$, et al. Tourniquet use for peripheral vascular injuries in the civilian setting. Injury. 2014;45:573-7.

13. Kauvar DS, Dubick MA, Walters TJ, Kragh JF. Jr. Systematic review of prehospital tourniquet use in civilian limb trauma. J Trauma Acute Care Surg. 2018;84:819-25.

14. Bonk C, Weston BW, Davis C, Barron A, McCarty O, Hargarten S. Saving Lives with Tourniquets: A Review of Penetrating Injury Medical Examiner Cases. Prehosp Emerg Care. 2020;24(4):494-9. https://doi.org/10.1080/10903127.201 9.1676344. Epub 2019 Dec 3

15. Kragh JF Jr, et al. Minor morbidity with emergency tourniquet use to stop bleeding in severe limb trauma: research, history, and reconciling advocates and abolitionists. Mil Med. 2011;176:817-23.

16. Lakstein $D$, et al. Tourniquets for hemorrhage control on the battlefield: a 4 year accumulated experience. J Trauma. 2003;54:221-5. 
17. Tapia NM, Suliburk J, Mattox KL. The initial trauma center fluid management of penetrating injury: a systematic review. Clin Orthop Relat Res. 2013;471: 3961-73.

18. Lögters $\mathrm{T}$, et al. [Interruption of the diagnostic algorithm and immediate surgical intervention after major trauma-incidence and clinical relevance. Analysis of the Trauma Register of the German Society for Trauma Surgery]. Unfallchirurg. 2010;113:832-8.

19. Ball CG, Williams BH, Tallah C, Salomone JP, Feliciano DV. The impact of shorter prehospital transport times on outcomes in patients with abdominal vascular injuries. J Trauma Manag Outcomes. 2013;7:11.

20. Dorlac WC, et al. Mortality from isolated civilian penetrating extremity injury. J Trauma. 2005;59:217-22.

21. Deutsche Gesellschaft für Unfallchirurgie. S 3 - Leitlinie Polytrauma/ Schwerverletzten-Behandlung. AWMF online, 446. (2016).

22. Geeraedts LM Jr, Kaasjager HA, van Vugt AB, Frolke JP. Exsanguination in trauma: A review of diagnostics and treatment options. Injury. 2009:40:11-20.

23. Winkelmann M, Wilhelmi M. [Prehospital resuscitation of patients with multiple injuries]. Unfallchirurg. 2014;117:99-104.

24. Hussmann B, et al. Does increased prehospital replacement volume lead to a poor clinical course and an increased mortality? A matched-pair analysis of 1896 patients of the Trauma Registry of the German Society for Trauma Surgery who were managed by an emergency doctor at the accident site. Injury. 2013;44:611-7.

25. Hussmann B, et al. [Lethality and outcome in multiple injured patients after severe abdominal and pelvic trauma. Influence of preclinical volume replacement - an analysis of 604 patients from the trauma registry of the DGU]. Unfallchirurg. 2011;114:705-12.

26. Dominguez KM, et al. Is routine tube thoracostomy necessary after prehospital needle decompression for tension pneumothorax? Am J Surg 205, 329-332; discussion 332 (2013).

27. Aul A, Klose R. [Invasive techniques in emergency medicine. II. Preclinical thorax drainage-indications and technique]. Anaesthesist. 2004;53:1203-10.

28. Rudolph M, Lange T, Göring M, Schneider NRE, Popp E. Resuscitative Clamshell-Thoracotomy in Prehospital and Inhospital Emergency Medicine: Indications, Requirements and Technique. Der Notarzt. 2019;35(04):199-207.

\section{Publisher's Note}

Springer Nature remains neutral with regard to jurisdictional claims in published maps and institutional affiliations.

Ready to submit your research? Choose BMC and benefit from:

- fast, convenient online submission

- thorough peer review by experienced researchers in your field

- rapid publication on acceptance

- support for research data, including large and complex data types

- gold Open Access which fosters wider collaboration and increased citations

- maximum visibility for your research: over $100 \mathrm{M}$ website views per year

At $\mathrm{BMC}$, research is always in progress.

Learn more biomedcentral.com/submissions 